\title{
Editorial
}

\section{Misconduct in scientific publications}

\section{Desvios de conduta em publicações científicas}

Sidney Glina

Editor-in-Chief

Last month I attended the I COPE Seminar Committee on Publication Ethics (I SCOPE) which happened in Florianópolis (SC) during the meeting of the Brazilian Society for Scientific Editors (ABEC - Portuguese acronym). It was the first time that such type of event took place in South America.

For those who do not know, COPE was founded in 1997 by a group of medical journal editors in the United Kingdom to discuss ethical problems in scientific publications. Now it has over 7000 members worldwide, has created a conduct code and advices editors on how to handle suspicious cases of ethical misconduct. The COPE guidelines may be freely assessed at www.publicationethics.org ${ }^{(1)}$.

The work of COPE and that of other similar entities has increased a great deal lately. Searching in PubMed the key words "retraction of publication" on December 8, 2012, I have found 2911 articles which has been retracted since 1973 .

Fang et al. ${ }^{(2)}$ reviwed 2047 articles indexed by PubMed on May $3^{\text {rd }}, 2012$ and showed that $21.3 \%$ were retractions attributable to error, $14.2 \%$ to duplicate publication, $9.8 \%$ to plagiarism and $43.4 \%$ to fraud or suspected fraud. According to these authors the percentage of scientific articles that were retracted because of fraud has had a tenfold increase since 1975. This study also revealed that the origin of the articles that had been retracted varies depending on their cause ${ }^{(2)}$. So, the United States, Germany, Japan and China were responsible for $75 \%$ of retractions due to fraud. As for plagiarism or redundant publication most of the articles came from India or China. These cases occurred more frequently in low impact journals while those retracted for fraud were related to high impact journals.

Fanelli ${ }^{(3)}$ published a meta-analysis evaluating the publications that investigated scientists behavior on misconduct. In the publication pool (18 cited) about $2 \%$ of researchers admitted to have fabricated, falsified or modified data at least once and up to $34 \%$ admitted a variety of other questionable practices. When they were asked about having knowledge of other colleagues' misconduct about $15 \%$ admitted that they knew of those practices.

These data show that even Science is far from being non contaminated by unethical behavior.

Plagiarism and redundant publication have their days numbered because of the appearance of a technology that identifies these practices, which are more common in developing countries ${ }^{(2,4)}$. However, fraud in research might have been stimulated.

Probably it is not by chance that misconduct practices are more common in high impact journals. The need to 
publish in these journals may lead researchers to falsify their data in order to obtain "perfect" results as well as papers with a novelty to be accepted. This need may be the pressure to gain or maintain high positions at academic scenario or even to get financial incentive which is given by many institutions and governments when one "publishes in high impact journals".

It is not easy to find a fraud and it may take as long as 5 years because most often they are planned by intelligent people that manage to deceive the reviewers so that they will only be found by a formal complaint after the publication. The blog Retraction Watch (http:// retractionwatch.wordpress.com) continuously publishes articles that are retracted and some complaints.
Thus, the work of the editor, the reviewer or even the reader has to be doubled. As the COPE coordinator Dr. Wagner said during I SCOPE "distrust all perfect research".

\section{REFERENCES}

1. Wager E. The Committee on Publication Ethics (COPE): objectives and achievements 1997-2012. Presse Med. 2012;41(9 pt1):861-6.

2. Fang FC, Steen RG, Casadevall A. Misconduct accounts for the majority of retracted scientific publications. Proc Natl Acad Sci USA. 2012;109(42): 17028-33.

3. Fanelli D. How many scientists fabricate and falsify research? A systematic review and meta-analysis of survey data. PLoS ONE. 2009;4(5):e5738. Review.

4. Stretton S, Brammich NJ, Keys JR, Monk JA, Ely JA, Haley C, et al. Publication misconduct and plagiarism retractions: a systematic, retrospective study. Curr Med Res Opin. 2012;28(10):1575-83. 